\title{
Acne Keloidalis Nuchae
}

\author{
Alexander K. C. Leung ${ }^{1}$ and Benjamin Barankin ${ }^{2}$ \\ ${ }^{1}$ Clinical Professor of Pediatrics, University of Calgary, Pediatric Consultant, Alberta Children's Hospital, Calgary, Alberta, Canada \\ ${ }^{2}$ Dermatologist, Medical Director and Founder, Toronto Dermatology Centre, Toronto, Ontario, Canada
}

\begin{abstract}
Acne keloidalis nuchae is a chronic inflammatory process involving the hair follicles on the occipital scalp and nape of neck, leading to the formation of keloidal papules and plaques. The condition is most prevalent in men of African descent with Afro-textured hair. Most cases occur in patients 14 to 25 years. The male to female ratio is approximately 20:1. Clinically, affected patients present with variable degrees of inflammation and keloid-like lesions at the nape of the neck and occipital scalp. Initial lesions consist of small, smooth, firm, discrete, dome-shaped, follicular papules with or without pustules. Over time, the papules may coalesce to form hairless, keloid-like plaques/nodules, that may be fringed with tufted hairs. The condition is often asymptomatic. The patient should be counseled to wear soft or no-collar skirts, avoid short haircuts, avoid picking/rubbing/scratching the affected area, and avoid wearing tight-fitting hats/helmet. Mild to moderate cases can be treated with potent or ultra-potent topical corticosteroids alone or in combination with topical antibacterials or topical retinoids. Intralesional corticosteroids should be considered for resistant cases and for the treatment of keloidal scarring. Laser therapy should be considered for hair removal and/or softening of keloidal plaques. If pustules and draining sinuses are present, oral antibiotics should be used in addition to topical antibiotics. Surgical excision is the cornerstone of management for extensive plaques and tumor-like masses.
\end{abstract}

\section{Introduction}

Acne keloidalis nuchae, also known as folliculitis keloidalis nuchae, is a chronic inflammatory process involving the hair follicles on the occipital scalp and nape of neck, leading to the formation of keloidal papules and plaques [1]. The disorder was first described in 1869 by Kaposi who called it "dermatitis papillaris capillitii" [2]. The term "acne keloidalis nuchae" was coined by Bazin in 1872 [3]. Although the term "acne keloidalis nuchae" is in popular use, it is a double misnomer. Unlike acne, comedones are not present in the involved area and unlike keloids, the scar-like lesions typically do not recur following excision and affected patients do not develop keloids elsewhere [4].

\section{Epidemiology}

Acne keloidalis nuchae is most prevalent in men of African descent with Afro-textured hair [5]. In one study, acne keloidalis nuchae was diagnosed in $4.7 \%$ of South African boys in the last year of school and $10.5 \%$ of South African men [5]. It is also frequently observed among Hispanic and Asian men and rarely observed among Caucasian men [1]. Most cases occur in patients 14 to 25 years of age when hair growth is maximum [1]. The male to female ratio is approximately $20: 1[1,6]$.

\section{Etiopathogenesis}

The primary pathologic process is acute inflammation of the hair follicle leading to a granulomatous foreign body reaction to hair growth with subsequent fibrosis [1]. The condition often occurs when tightly curled coarse hairs are cut obliquely in the process of shaving, giving them sharp points which facilitate their re-entry into the skin, thereby invoking an inflammatory response. Predisposing factors include coarse, frizzy hair, close haircuts, short, stocky neck, constant irritation by shirt collars, wearing tight-fitting hats or helmets, excess androgens or increased sensitivity to androgens, increased mast cell density in the occipital area, medications (cyclosporine, diphenylhydantoin, carbamazepine), seborrheic dermatitis, aberrant immune reaction, heat, and humidity $[1,4,5,7]$.

\section{Histopathology}

Histological examination of lesions in the early stages reveal dense follicular and perifollicular inflammatory infiltrate of neutrophils and lymphocytes $[4,6]$. In the more advanced stages, disrupted and broken hair follicles surrounded by granulomatous inflammation, perifollicular abscess, and dermal fibrosis may be seen $[4,6]$.

\section{Clinical manifestations}

Clinically, affected patients present with variable degrees of inflammation and keloid-like lesions on the nape of the neck and occipital scalp (Figure 1) [4]. Initial lesions consist of small, smooth, firm, discrete, dome-shaped, follicular papules with or without pustules [1,6]. Characteristically, comedones are not present in the affected area. As the disease progresses, more papules may appear and they may coalesce to form hairless, keloid-like plaques/nodules, that may be fringed with tufted hairs (multiple hair shafts emerging from a single follicular opening) $[1,6]$. Inflammatory and fibrotic lesions often coexist. Crusting and excoriation may be evident [4]. In advanced or severe cases, disfiguring tumor-like masses, abscesses, and pus-exuding sinus tracts may be present $[1,6]$. Acne keloidalis nuchae is often

Correspondence to: Dr. Alexander K.C. Leung, Clinical Professor of Pediatrics, University of Calgary, Pediatric Consultant, Alberta Children's Hospital, \#200, 233 - 16th Avenue NW, Calgary, Alberta, Canada T2M 0H5, Tel: (403) 2303322; E-mail: aleung@ucalgary.ca

Key words: keloid-like, papules, plaques, nodules, nape, African, male

Received: February 10, 2015; Accepted: March 04, 2015; Published: March 07, 2015 


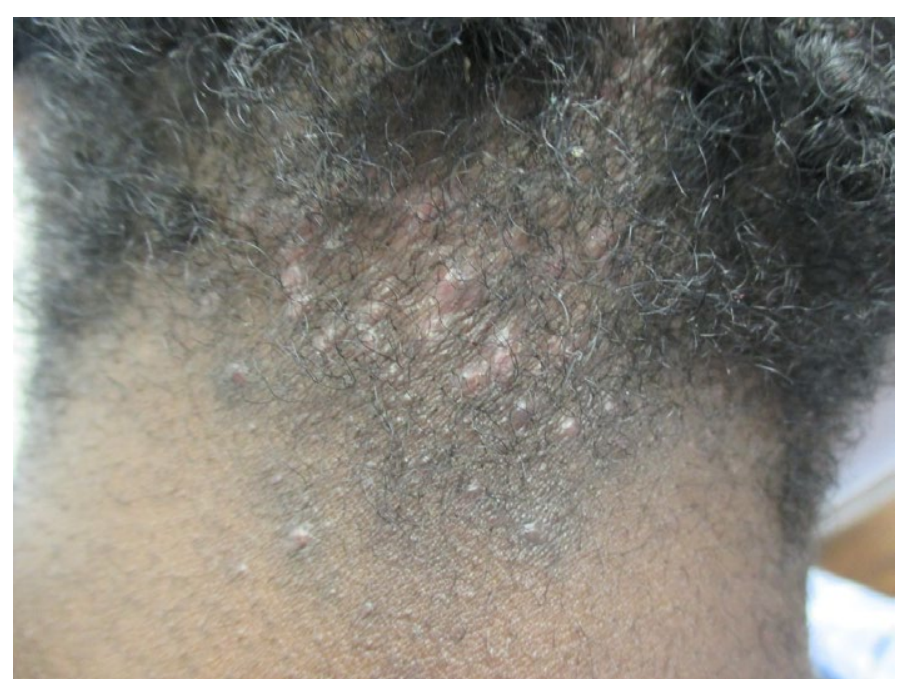

Figure 1. Acne keloidalis nuchae with characteristic involvement of the posterior scalp and nape of the neck.

asymptomatic. However, patients sometimes experience mild burning, pruritus, or pain [1].

\section{Diagnosis}

The diagnosis is mainly clinical. Biopsy is usually not necessary unless the diagnosis is in doubt. Referral to a dermatologist is warranted if the diagnosis is uncertain.

\section{Differential diagnosis}

Differential diagnosis includes acne vulgaris, acne mechanica, molluscum contagiosum, tinea capitis, bacterial folliculitis, folliculitis decalvans, dissecting cellulitis of the scalp, lichen planopilaris, impetigo, follicular cutaneous t-cell lymphoma, and hidradenitis suppurativa [4].

\section{Complications}

Complications include secondary bacterial infection, formation of a draining sinus tract, and scarring alopecia. The quality of life may be adversely affected due to the cosmetic disfigurement.

\section{Prognosis}

Acne keloidalis nuchae tends to run a chronic course with episodic flares [4]. Over time, the disease tends to be less active in terms of inflammation [4]. Without treatment, keloidal lesions usually persist
[4].

\section{Management}

The patient should be counseled to wear soft or no-collar skirts, avoid short haircuts, avoid picking/rubbing/scratching the affected area, and avoid wearing tight-fitting hats/helmets $[1,4]$.

Mild to moderate cases can be treated with potent or ultrapotent topical corticosteroids (e.g., $0.05 \%$ clobetasol propionate) alone or in combination with topical antibacterials (e.g., clindamycin, erythromycin, benzoyl peroxide) or topical retinoids (e.g., tretinoin, adapalene, tazarotene) [1]. Recently, it has been shown that targeted ultraviolet $\mathrm{B}$ phototherapy can be useful to improve the clinical appearance of the lesions [8].

Intralesional corticosteroids (e.g., triamcinolone acetonide) should be considered for resistant cases and for the treatment of keloidal scarring [1]. Laser therapy (e.g., carbon dioxide or neodymiun:yttrium aluminum garnet) should be considered for hair removal and/or softening of keloidal plaques $[9,10]$.

If pustules and draining sinuses are present, bacterial culture and sensitivity should be performed and oral antibiotics (e.g., doxycycline, minocycline) should be used in addition to topical antibiotics.

Surgical excision is the cornerstone of management for extensive plaques and tumor-like masses $[4,6]$. Recurrences are more likely if the plane of excision does not lie below the base of the hair follicles.

\section{References}

1. Lookingbill DP, Spangler N, Helm KF (1993) Cutaneous metastases in patients with metastatic carcinoma: a retrospective study of 4020 patients. J Am Acad Dermatol 29 . 228-236. [Crossref]

2. Attili VSS, Bapsy PP, Lokanatha D, Rajashekar H, Ramachandra C (2008) Cutaneous metastasis in a case of carcinoma stomach. Austral-Asian journal of cancer 7: 233-34.

3. Jaw-Yuan W, Chee-Yin C, Yu-Chung S, Kwan-Ming S, Yu-Sheng H, et al. (2005) cutaneousmetastasis from gastric adenocarcinoma: a case report. Kaohsiung J Med Sci 21: 329-333.

4. Eerman H (1969) Some aspects of cutaneous malignancy. Arch Dermatol 99: 617-626. [Crossref]

5. Chatni S, Peshwe H (2005) Cutaneous metastases in carcinoma stomach. Indian J Gastroenterol 24: 133. [Crossref]

6. Sood A, Midha V, Sekhon JS, Sidhu SS (1998) Generalized cutaneous metastases from carcinoma stomach. Am J Gastroenterol 93: 1601. [Crossref]

7. Sarid D, Wigler N, Gutkin Z, Merimsky O, Leider-Trejo L, et al. (2004) Cutaneous and subcutaneous metastases of rectal cancer. Int J Clin Oncol 9: 202-205. [Crossref]

Copyright: (2015 Leung AKC. This is an open-access article distributed under the terms of the Creative Commons Attribution License, which permits unrestricted use, distribution, and reproduction in any medium, provided the original author and source are credited. 